Çukurova Üniversitesi Mühendislik Mimarlık Fakültesi Dergisi, 35(1), ss. 115-125, Mart 2020

Çukurova University Journal of the Faculty of Engineering and Architecture, 35(1), pp. 115-125, March 2020

\title{
Doğal Bir Madde Olan Nişastadan Aktif Karbon Hazırlanması, Karakterizasyonu ve Adsorbent Olarak Kullanımı
}

\author{
Ömer KAZAK ${ }^{* 1,2}$ \\ ${ }^{1}$ Necmettin Erbakan Üniversitesi, Mühendislik ve Mimarlık Fakültesi, Çevre Mühendisliği Bölümü, \\ Konya \\ ${ }^{2}$ Necmettin Erbakan Üniversitesi, Bilim ve Teknoloji Araştırma ve Uygulama Merkezi (BİTAM), Konya
}

Geliş tarihi: 31.07.2019 Kabul tarihi: 15.05 .2020

$\ddot{\mathbf{O} z}$

$\mathrm{Bu}$ çalışmada, doğal bir madde olan nişastadan kimyasal aktivasyon yöntemi ile aktif karbon hazırlanmıştır. Nişastanın hidrotermal karbonizasyonu sonucu karbon kürecikler elde edilmiştir. Kimyasal aktivasyon işlemi $800{ }^{\circ} \mathrm{C}$ 'de $\mathrm{NaOH}$ ile gerçekleştirilmiştir. Kimyasal aktivasyonun karbon küreciklerin yapısı ve morfolojisi üzerine etkileri FT-IR, SEM ve BET ve zeta potansiyeli teknikleri kullanılarak değerlendirilmiştir. Aktivasyon işlemi sonucunda, yüksek spesifik yüzey alanına $\left(968 \mathrm{~m}^{2} / \mathrm{g}\right)$ sahip mikro gözenekli $\left(0,592 \mathrm{~cm}^{3} / \mathrm{g}\right)$ aktif karbon elde edilmiştir. Aktif karbonun sudaki kongo kırmızısının giderimin de adsorbent olarak kullanılma potansiyeli farklı deneysel şartlar altında araştırılmıştır. Aktif karbonun kongo kırmızısı için Langmuir adsorpsiyon kapasitesi 117,65 mg/g'dir. Rejenarasyon çalışmaları aktif karbonun adsorpsiyon kapasitesinde bir değişiklik olmadan kongo kırmızısı giderimi için en az altı kez kullanılabilir olduğunu göstermiştir.

Anahtar Kelimeler: Hidrotermal karbonizasyon, Aktif karbon, Kongo kırmızıs1, Adsorpsiyon

\section{Preparation of Activated Carbon from Natural Starch, its Characterization and Use as an Adsorbent}

\begin{abstract}
In this study, activated carbon was prepared from starch which is a natural substance by chemical activation method. Carbon spheres were obtained by hydrothermal carbonization of starch. Chemical activation process was carried out with $\mathrm{NaOH}$ at $800{ }^{\circ} \mathrm{C}$. The effects of chemical activation on the structure and morphology of carbon spheres were evaluated using FT-IR, SEM and BET and zeta potential techniques. As a result of the activation process, the activated carbon having microporous $\left(0,592 \mathrm{~cm}^{3} / \mathrm{g}\right)$ with high specific surface area $\left(968 \mathrm{~m}^{2} / \mathrm{g}\right)$ was obtained. The potential of using activated carbon as an adsorbent for removal of congo red in water was investigated under several experimental conditions. Langmuir adsorption capacity of active carbon for congo red is $117,65 \mathrm{mg} / \mathrm{g}$. Regeneration studies have shown that the activated carbon can also be used at least six times for the removal of congo red with no change in its adsorption capacity.
\end{abstract}

Keywords: Hydrothermal carbonization, Activated carbon, Congo red, Adsorption

*Sorumlu yazar (Corresponding author): Ömer KAZAK, okazak@erbakan.edu.tr 


\section{GíRiş}

Boyar maddeler tekstil, kâğıt, lastik, deri, yiyecek vb. çeşitli endüstrilerde yaygın olarak kullanılmaktadır [1]. Boyar madde içeren endüstriyel atık suların akarsu, göl, deniz ve diğer alıcı ortamlara deşarj edilmesi önemli bir çevre sorunu oluşturmakta ve boyar maddelerin birçoğu sudaki yaşamın yanı sıra insanlar için kanserojen ve mutajen özelliklere sahiptir [2]. Bu sebeplerden dolayı boyar madde içeren endüstriyel atık sular alıcı ortama deşarj edilmeden önce arıtılmalıdır.

Boyar madde içeren atık suların arıtımı için kimyasal oksidasyon, elektrokoagülasyon [3], nano filtrasyon [4], ters ozmoz ve adsorpsiyon [5] gibi farklı yöntemler kullanılmaktadır. $\mathrm{Bu}$ yöntemler arasında, adsorpsiyon uygulama kolaylığı ve yüksek verimliliğe sahip olması nedeni ile su ortamından boyar maddelerin giderimin de en uygun ve etkili yöntemlerden biri olarak kabul edilmektedir [6,7]. Boyar madde içeren atık suların adsorpsiyon yöntemi ile arıtımına yönelik son yıllardaki çalışmalar, verimli, ucuz ve yenilenebilir adsorbent malzemelerin kolay ve çevre dostu tekniklerle hazırlanmasına odaklanmıştır [8]. Hidrotermal karbonizasyon (HTC) işlemi düşük işletme maliyeti ve organik çözücü kullanılmaması gibi avantajları, HTC işleminin karbon esaslı adsorbentlerin hazırlanması için düşük maliyet ve çevreye zararsız yöntem olarak değerlendirilmektedir [9]. Karbon malzemelerin hazırlanmasında geliştirilen bu yöntemin önemi göz önüne alındığında HTC alternatif bir teknik olarak ortaya çıkmıştır. HTC yöntemi ile elde edilen karbon esasl malzemeler fiziksel veya kimyasal yöntemlerle adsorpsiyon kapasitesi büyük, geniş yüzey alanına sahip aktif karbonların üretimi önem taşımaktadır. HTC yöntem ile hazırlanmış karbon esaslı malzemeler, yüzey alanını ve adsorbentin giderim performansını artırmak için farklı aktivasyon reaktifleri $(\mathrm{KOH}$, $\left.\mathrm{NaOH}, \mathrm{H}_{3} \mathrm{PO}_{4}\right)$ ile kimyasal yöntemle aktive edilirler [10].

Bu çalışmada, yenilenebilir, doğal, ucuz bir madde olan nişasta, HTC tekniği ile karbon esaslı karbon kürecikler elde edilmesi için tercih edilmiştir. Elde edilen karbon kürecikler $\mathrm{NaOH}$ ile kimyasal olarak aktive edilerek aktif karbon hazırlanması hedeflenmiştir. Ürünlerin yapısal ve morfolojik özelikleri termal gravimetrik analiz (TGA), taramalı elektron mikroskobu (SEM), fourier dönüşümlü kızılötesi spektroskopisi (FT-IR), Brunauer, Emmet ve Teller (BET) teknikleri yanında, gözenek boyut dağılımı-boşluk hacmi ve zeta potansiyeli analizleri ile incelenmiştir. Aktif karbonun su ortamındaki model organik kirletici (kongo kırmızısı) adsorpsiyonunda kullanılabilme potansiyelinin araştırılması amaçlanmıştır.

\section{MATERYAL VE METOT}

\subsection{Kullanılan Kimyasallar}

Deneysel çalışmalarda kullanılan kimyasallar analitik saflıktadır. Patates nişastası $\left(25^{\circ} \mathrm{C}\right.$ 'de $20 \mathrm{~g} / \mathrm{L} \quad \mathrm{H}_{2} \mathrm{O}$ 'da $\mathrm{pH}$ değeri 6-7,5, $50 \mathrm{~g} / \mathrm{L}$ çözünürlüğe sahip) $\mathrm{NaOH}, \mathrm{HCI}, \mathrm{NaCI}$, $\left(\mathrm{NH}_{4}\right)_{2} \mathrm{Fe}\left(\mathrm{SO}_{4}\right)_{2}$ Merck firmasından, kongo kırmızısı Sigma-Aldrich firmasından temin edilmiştir.

\subsection{HTC Yöntemi ile Karbon Küreciklerin Hazırlanması}

Nişasta önceki çalışmalarımızda açıklandığı şekilde HTC yöntemi ile karbon küreciklere dönüştürülmüştür [11]. Bu yönteme göre, $1 \mathrm{~g}$ nişasta $20 \mathrm{~mL}$ saf suda 30 dakika manyetik karıştırıcı ile karıştırılmıştır. Daha sonra $10 \mathrm{~mL}$, 0,5 $\mathrm{mM}\left(\mathrm{NH}_{4}\right)_{2} \mathrm{Fe}\left(\mathrm{SO}_{4}\right)_{2}$ ilave edilerek karıştırma işlemi tamamlanmıştır. $50 \mathrm{~mL}$ kapasiteye sahip teflon kaplı basınca dayanıklı paslanmaz çelik otaklav içerisine konulmuş ve $180{ }^{\circ} \mathrm{C}$ 'de 12 saat bekletilmiştir. Elde edilen karbon kürecikler saf su ile y1kanıp $100{ }^{\circ} \mathrm{C}$ 'de kurutulmuştur. HTC yöntem ile aktivasyon işlemi öncesi karbonca zengin ürün elde edilmiştir.

\subsection{Karbon Küreciklerin Aktivasyonu}

Karbon küreciklerin kimyasal aktivasyonu için $\mathrm{NaOH}$ kullanılmıştır. $1 \mathrm{~g}$ karbon kürecik ve $1 \mathrm{~g}$ $\mathrm{NaOH}$ (1:1, w:w) karıştırılıp paslanmaz çelik reaktörlü yatay firında (Protherm, PZF 12/50/500) azot gazı ortamında (180 mL/dakika) $800{ }^{\circ} \mathrm{C} 1$ saat 
bekletilmesiyle gerçekleştirilmiştir. Elde edilen aktif karbon $\mathrm{pH}$ 7-7,5 aralığına ulaşana kadar saf su ile yıkanmış ve $100{ }^{\circ} \mathrm{C}$ 'de kurutulmuştur. Piroliz işlemi esnasında orta çıkan atık gaz, gaz yıkama şişesinden geçirildikten sonra filtre sistemi bulunan çeker ocak ile ortamdan uzaklaştırılmıştır.

\subsection{Karakterizasyon Çalışmaları}

Karbon küreciklerin termal davranışı termogravimetrik analiz cihazı (Setaram, Setsys Evolution) ile $25 \mathrm{~mL} /$ dakika akış hızındaki azot gazı altında, $10{ }^{\circ} \mathrm{C} /$ dakika sıcaklık artışı ile $50-900{ }^{\circ} \mathrm{C}$ aralığında incelenmiştir. Ürünlerin (karbon kürecik ve aktif karbon) FT-IR spektrumları 750-4000 $\mathrm{cm}^{-1}$ dalga boyu aralığında FT-IR spektrofotometresi ile (Perkin Elmer 1600) elde edilmiştir. Ürünlerin yüzey görüntüleri SEM (JEOL 5600-LU, UK) kullanılarak elde edilmiştir. BET yüzey alanı ve gözenek boyut dağılımı, BET analizörü (Quantachrome Quadrasorb evo) kullanılarak $77 \mathrm{~K}$ 'de $\mathrm{N}_{2}$ adsorpsiyon izotermlerine göre belirlenmiştir. Toplam gözenek hacmi $\left(\mathrm{V}_{\text {toplam}}\right)$, NLDFT (Non Local Density Functional Theory) metoduna göre $\mathrm{P} / \mathrm{P}_{\mathrm{o}}=0,95$ 'de adsorbe edilen $\mathrm{N}_{2}$ miktarından elde edilmiştir. Adsorpsiyon çalışmalarında kullanılan son ürünün zeta potansiyeli ise Zetasizer cihazı (Malvern) kullanılarak belirlenmiştir.

\subsection{Adsorpsiyon Çalışmaları}

Adsorpsiyon çalışmalarında, aktif karbon'un adsorpsiyon giderim veriminin belirlenmesi için model boyar kirletici olarak kongo kırmızısı seçilmiştir. Adsorpsiyon denemeleri için 0,01 g aktif karbon alınarak, farklı konsantrasyonlarda (10-300 mg/L) 0,01 M iyonik şiddetteki kongo kırmızısı içeren $20 \mathrm{~mL}$ çözelti içinde dağıtılmıştır ve sıcaklık kontrollü yatay çalkalayıcıda $25{ }^{\circ} \mathrm{C}^{\prime} \mathrm{de}$ 220 rpm'de çalkalanmıştır. Belirlenen konsantrasyondaki kongo kırmızı çözeltisi 1000 $\mathrm{mg} / \mathrm{L}$ stok çözeltiden elde edilmiştir. Çözeltinin pH ayarlaması $0,1 \mathrm{M} \mathrm{HCl}$ ve/veya $0,1 \mathrm{M} \mathrm{NaOH}$ çözeltileri ile gerçekleştirilmiştir. Çözeltilerin iyonik şiddeti $0,01 \mathrm{M} \mathrm{NaCI}$ ile ayarlanmıştır. Kongo kırmızısı başlangıç anındaki ve adsorpsiyondan sonra çözeltilerde kalan konsantrasyonu UV-vis spektrofotometre (Hach
Lange, DR 5000) ile $498 \mathrm{~nm}$ dalga boyunda tayin edilmiştir.

Kongo kırmızısının adsorbent tarafindan tutulan miktarı (q, mg/g), başlangıç konsantrasyonu $\left(\mathrm{C}_{\mathrm{o}}\right.$, $\mathrm{mg} / \mathrm{L})$ ve adsorpsiyondan sonra çözeltide kalan kirletici konsantrasyonundan $\left(\mathrm{C}_{\mathrm{e}}, \mathrm{mg} / \mathrm{L}\right)$ hareket ile çözelti hacmi $(\mathrm{V}, \mathrm{L})$ ve kullanılan adsorbent miktarı (m, g) dikkate alınarak Eşitlik 1'e göre hesaplanmıştır.

$q=\frac{\left(C_{0}-C_{e}\right)}{m} x V$

Kongo kırmızısı adsorpsiyonu üzerine, çözelti $\mathrm{pH}$ 'sının $(\mathrm{pH}=3-11)$, temas süresinin (5-120 dakika), başlangıç kongo kırmızısı konsantrasyonunun (10-300 $\mathrm{mg} / \mathrm{L})$ etkisi ve adsorbentin rejenerasyonu ile yeniden kullanılabilirliği incelenmiştir.

\section{BULGULAR VE TARTIŞMA}

\subsection{Aktivasyon Sıcaklığının Belirlenmesi}

İlk olarak karbon küreciğin azot atmosferi altındaki termal davranışı incelenmiştir. TGA sonucu elde edilen termogram Şekil 1'de gösterilmiştir.

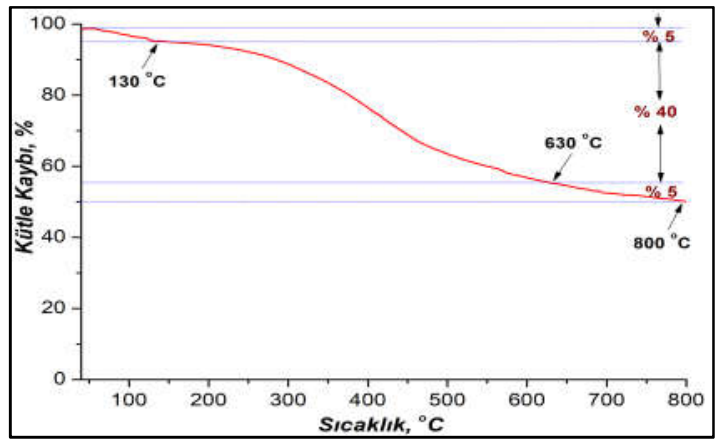

Şekil 1. Karbon kürecik termal davranışı

Şekil 1'e göre, $130{ }^{\circ} \mathrm{C}$ 'ye kadar ulaşan sıcaklık artışı ile \%5'lik kütle kaybı gerçekleşmiştir. $\mathrm{Bu}$ kütle kayb1 karbon kürecik de bulunan $\mathrm{H}_{2} \mathrm{O}$ 'nun uzaklaşmasından kaynaklanmaktadır [12]. 130-630 ${ }^{\circ} \mathrm{C}$ arasında gerçekleşen kütle kaybı (\%40) ise karbon kürecik bünyesindeki karbonların $\mathrm{CO}$ 
ve $\mathrm{CO}_{2}$ olarak yapıdan uzaklaşmasından kaynaklanmaktadır [13]. $630 \quad{ }^{\circ} \mathrm{C}$ 'den $\quad$ sonraki sıcaklıklarda kütle kaybı (\%5) yapısındaki karbon bileşiklerin uzaklaşmasından kaynaklanmaktadır [14]. Şekil 1'deki TGA sonucuna göre $630^{\circ} \mathrm{C}$ 'den sonraki sıcaklıklarda kütle kaybının oldukça az ve karbon küreciğin kararlı bir yapıya ulaştığ 1 ifade edilebilir. $\mathrm{Bu}$ sonuca göre karbon küreciğin $\mathrm{NaOH}$ ile aktive edilme sicaklığ $1800 \quad{ }^{\circ} \mathrm{C}$ olarak belirlenmiştir.

\subsection{Karakterizasyon Çalışmaları}

Karbon küreciklerin ve $\mathrm{NaOH}$ ile kimyasal olarak aktive edilmesi sonucu elde edilen aktif karbonun karakterizasyonları FT-IR, BET yüzey alanı, gözenek hacimleri, gözenek boyut dağılımı ve SEM ile incelenmiştir. Elde edilen ürünlere (karbon kürecik ve aktif karbon) ait FT-IR spektrumları Şekil 1'de gösterilmiştir.

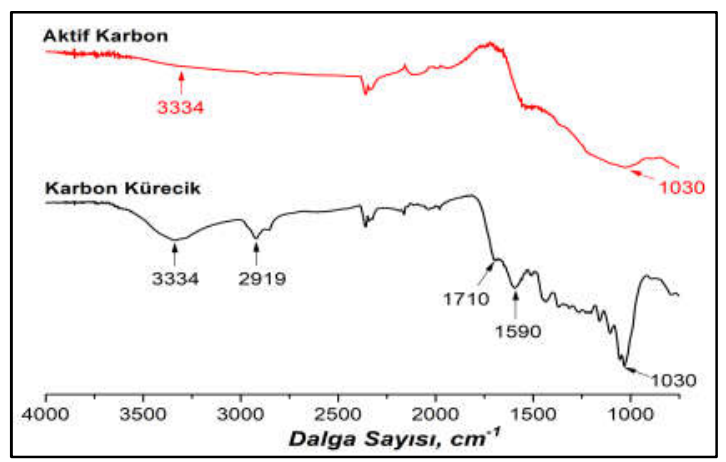

Şekil 1. Karbon kürecik ve Aktif karbon ürünlerine ait FT-IR spektrumları

Karbon küreciğe ait FT-IR spektrumunda, $3334 \mathrm{~cm}^{-1}$ deki band-OH grubundan kaynaklanmaktadır [15]. $2919 \mathrm{~cm}^{-1}$ de görülen band alifatik $\mathrm{C}-\mathrm{H}$ gerilme titreşiminden ileri gelmektedir. $1710 \mathrm{~cm}^{-1}$ de, $1590 \mathrm{~cm}^{-1}$ de ve $1030 \mathrm{~cm}^{-1}$, de görülen bandlar sirasiyla $\mathrm{C}=\mathrm{O}, \mathrm{C}=\mathrm{C}$ ve $\mathrm{C}-\mathrm{O}$ titreşimlerinden kaynaklandığı görülmektedir [16]. Şekil 1 incelendiğinde, aktif karbona ait FT-IR spektrumundaki bandların şiddetinde bir azalma olduğu görülmektedir. Bu durum aktivasyon sicaklığında fonksiyonel grupların yapıdan uzaklaşmasından kaynaklanmaktadır.
Karbon kürecik ve aktif karbonun BET yüzey alanları, toplam, mikro ve mezo gözenek hacimleri incelenmiş ve sonuçlar Çizelge 1'de verilmiştir.

Çizelge 1. Karbon kürecik ve aktif karbon ürünlerine ait yüzey alanları ve gözenek hacimleri

\begin{tabular}{|l|c|c|c|c|}
\hline Ürün & $\begin{array}{c}\text { Yüzey } \\
\text { alan1, } \\
\mathrm{m}^{2} / \mathrm{g}\end{array}$ & $\begin{array}{c}\mathrm{V}_{\text {toplam }}, \\
\mathrm{cm}^{3} / \mathrm{g}\end{array}$ & $\begin{array}{c}\mathrm{V}_{\text {mikro }}, \\
\mathrm{cm}^{3} / \mathrm{g}\end{array}$ & $\begin{array}{c}\mathrm{V}_{\text {mezo }}, \\
\mathrm{cm}^{3} / \mathrm{g}\end{array}$ \\
\hline Karbon Kürecik & 4 & 0,001 & - & - \\
\hline Aktif Karbon & 968 & 0,684 & 0,592 & $0,092^{*}$ \\
\hline
\end{tabular}

${ }^{*} V_{\text {mezo }}=V_{\text {toplam }}-V_{\text {mikro }}$

HTC sonucu elde edilen karbon küreciğin yüzey alanın (4 $\left.\mathrm{m}^{2} / \mathrm{g}\right)$ oldukça küçük olduğu tespit edilmiştir. Karbon küreciğin $\mathrm{NaOH}$ ile aktivasyonu sonucu ise, büyük miktarda gözenekli yapının oluştuğu ve bunun sonucunda yüksek yüzey alanına sahip aktif karbon elde edilmiştir. Elde edilen bu sonuca göre, oldukça sinırlı bir yüzey alanına sahip karbon küreciğin $\mathrm{NaOH}$ ile aktivasyonu sonucu gözenek hacminin, özellikle mikro gözenek hacmini $\left(\mathrm{V}_{\text {mikro }}=0,592 \mathrm{~cm}^{3} / \mathrm{g}\right)$ ve yüzey alanını $\left(968 \mathrm{~m}^{2} / \mathrm{g}\right)$ önemli ölçüde artırdığı tespit edilmiştir.

Ürünlere ait gözenek boyut dağılımları Şekil 3'de gösterilmiştir. Genel olarak aktif karbon ürünün mikro gözenek $(<20 \AA)$ dağılımına sahip olduğu görülmektedir. $\mathrm{Bu}$ sonuçlar ürünlere ait mikro ve mezo gözenek hacimleri ile de uyumludur.

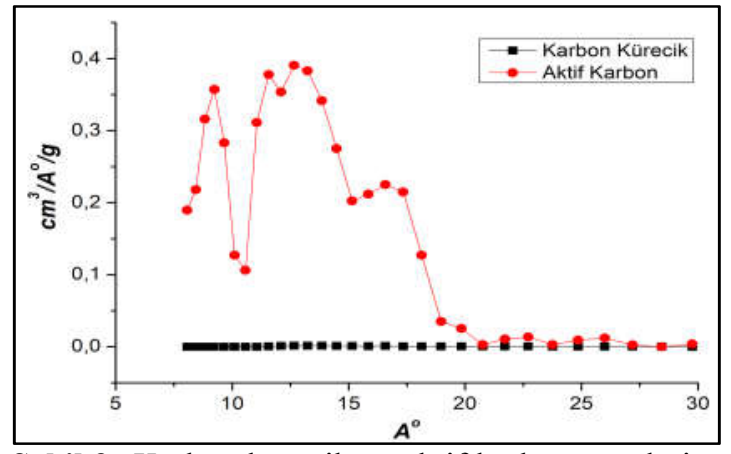

Şekil 3. Karbon kürecik ve aktif karbon ürünlerine ait gözenek boyut dağılımı

Karbon kürecik ve aktif karbon ürünlerine ait yüzey morfolojilerinin gösterildiği SEM 
görüntüleri Şekil 4'de verilmiştir. HTC yöntemi ile nişastanın karbon esaslı küreciklere dönüştürülebildiği görülmektedir. Yüzeyi oldukça düz bir yapıya sahip karbon kürecikler $\mathrm{NaOH}$ ile aktivasyon işlemi sonucunda yüzeyde çok fazla gözeneklerin oluştuğu tespit edilmiştir.
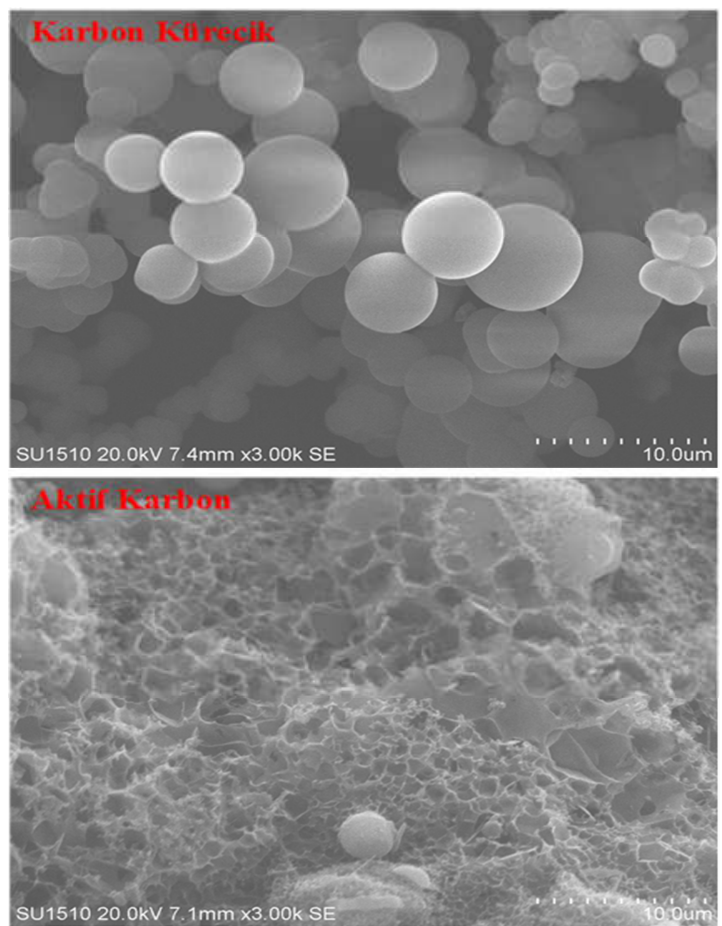

Şekil 4. Karbon kürecik ve aktif karbon ürünlerine ait yüzey görüntüleri

\subsection{Adsorpsiyon Çalışmaları}

\subsection{1. Çözelti pH'sının Etkisi}

Kirleticilerin çözelti ortamından giderimine etki edebilen önemli parametre çözeltinin $\mathrm{pH}$ değeridir. $\mathrm{Bu}$ sebepten dolayı, $50 \mathrm{mg} / \mathrm{L}$ 'lik kongo kırmızısı çözeltisinin pH değeri 3-11 arasında değiştirilip elde edilen aktif karbon ürünün adsorpsiyon verimi incelenmiştir. Şekil 5'de verilen sonuçlar incelendiğinde, adsorbentin giderim veriminin pH'dan bağımsız olduğunu, pH'ın kongo kırmızısı giderimi üzerinde önemli bir etkisi olmadığını göstermiştir. Şekil 5'de görüldüğü gibi aktif karbon ürünün $\mathrm{pH}$ 3-11 aralığındaki zeta potansiyel değerleri $(-8,03$ ile $-13,2)$ arasında değişmektedir. Çözeltinin $\mathrm{pH}$ değeri arttıkça adsorbentin negatif yükünü artırmıştır. Çözelti pH'ının yükselmesi sonucu adsorbentin negatif yüzey yükündeki artış sebebi ile elektrostatik bir itme kuvvetinin oluşması ile anyonik formdaki kongo kırmızı giderim veriminin azalması beklenmektedir. Li ve arkadaşlarının ipek böceği koza atığından elde etmiş olduğu aktif karbon ile kongo kırmızı giderimin de $\mathrm{pH}$ 2'de maksimum giderim verimi bulmuşlardır. $\mathrm{Bu}$ durumu, $\mathrm{pH} 2$ 'de pozitif yüklü adsorbent ile negatif yüklü kongo kırmızısı arasındaki elektrostatik etkileşimle açıklamışlardır [17]. Daha önce ifade edildiği gibi kongo kırmızısı giderim verimine $\mathrm{pH}$ 'ın önemli bir etkisi olmadığı belirlenmiştir. Adsorbentin kongo kırmızı giderimin de zeta potansiyelinin etkisinden ziyade, adsorbentin yüzey alanın oldukça büyük olması ve gözenek boyut dağılımın rol aldığı ifade edilebilir. Elde edilen bu sonuç, literatürdeki çalışmalar ile de uyumludur. Örneğin, Dong ve arkadaşlarının silkattan elde etmiş olduğu adsorbent ile kongo kırmızısı giderimi için yapmış oldukları çalışmada, $\mathrm{pH}$ etkisinin kongo kırmızısı giderim kapasitesinde önemli değişimin olmadığını belirlemişlerdir [18]. Diğer bir örnekte ise, Cheng ve arkadaşlarının yapmış olduğu çalışmada rodamin B'nin sulu çözeltiden giderimi için arıtma çamurundan hazırlamış olduğu aktif karbon kullanmışlardır. $\mathrm{pH}$ değişiminin rodamin B giderim verimine önemli bir etkisi olmadığı tespit etmişlerdir [19].

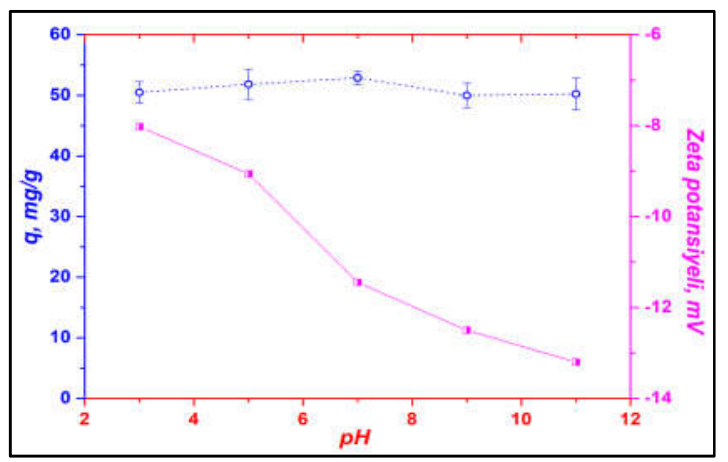

Şekil 5. Aktif karbon ile kongo kırmızısı giderimi üzerine çözelti $\mathrm{pH}$ 'ının etkisi $\left(\mathrm{C}_{\mathrm{o}}\right.$ : 50 $\mathrm{mg} / \mathrm{L}$, temas süresi: 2 saat, adsorbent miktar1: $0,5 \mathrm{~g} / \mathrm{L}$, iyonik şiddet: $0,01 \mathrm{M}$, sıcaklık: $25{ }^{\circ} \mathrm{C}$, karıștırma hızı: $220 \mathrm{rpm}$ ) 
Aktif karbonun $\mathrm{pH}$ ayarlaması yapılmadan kullanılması çevresel ve pratik uygulamalar için önemli bir avantajdır. Bu sebeple kongo kırmızısı adsorpsiyon çalışmasının diğer aşamalarında çözelti pH'larında bir ayarlama yapılmamıştır.

\subsubsection{Temas Süresinin Etkisi}

Aktif karbon ürünü ile sudaki kongo kırmızısı giderimine temas süresinin etkisi incelenmiş ve elde edilen sonuçlar Şekil 6'da verilmiştir.

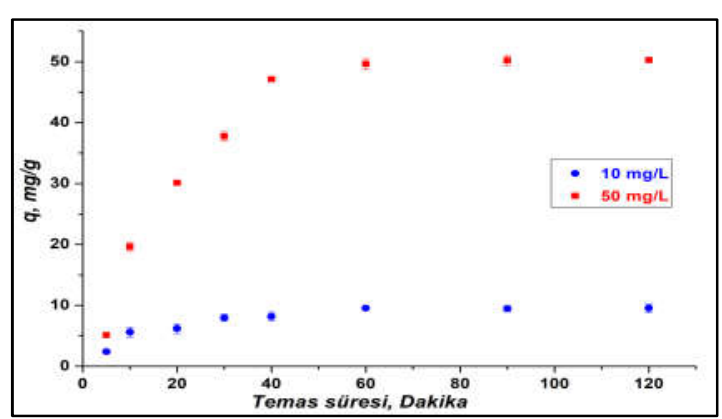

Şekil 6. Aktif karbon ile kongo kırmızısı giderimi üzerine temas süresinin etkisi $\left(\mathrm{C}_{0}: 10\right.$, $50 \mathrm{mg} / \mathrm{L}, \quad \mathrm{pH}:$ 7,05-7,20, adsorbent miktar1: $0,5 \mathrm{~g} / \mathrm{L}$, iyonik şiddet: $0,01 \mathrm{M}$, sıcaklık: $25^{\circ} \mathrm{C}$, karıştırma hızı: 220 rpm)

İki farklı konsantrasyon (10 ve $50 \mathrm{mg} / \mathrm{L})$ için adsorbentin ilk 10 dakikada kongo kırmızısının büyük bir kısmını adsorbe etmiştir. Bu kısa sürede yüksek miktarda kongo kırmızısı giderimi adsorbentin yüzeye alanın (968 $\left.\mathrm{m}^{2} / \mathrm{g}\right)$ büyük olmasına atfedilebilir. Kongo kırmızısı giderimi için gerekli temas süresi 60 dakikadır (Şekil 6). $10 \mathrm{mg} / \mathrm{L}$ konsantrasyonundaki kongo kırmızısi çözeltisinin 60. dakika'ya kadar renginin tamamına yakının giderildiği Şekil 7'de de gösterilmiştir.

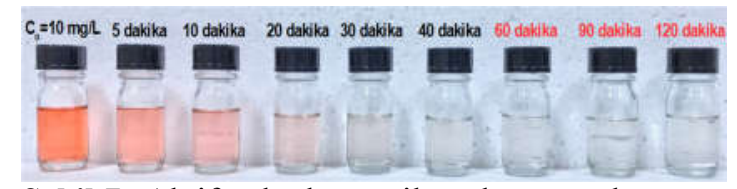

Şekil 7. Aktif karbon ile kongo kırmızısı giderimin de çözelti renginde zamanla meydana gelen azalma $\left(\mathrm{C}_{\mathrm{o}}: 10 \mathrm{mg} / \mathrm{L}, \mathrm{pH}\right.$ : 7,05-7,20, adsorbent miktar1: $0,5 \mathrm{~g} / \mathrm{L}$, iyonik şiddet: $0,01 \mathrm{M}$, sicaklık: $25{ }^{\circ} \mathrm{C}$, karıştırma hızı: 220 rpm)

\subsubsection{Adsorpsiyon İzoterm Analizi}

Adsorpsiyon izotermi, sabit sıcaklıkta, denge çözeltisinde kalan madde konsantrasyonuna karş1 adsorbentin birim kütlesinin tutmuş olduğu madde miktarı grafiğe aktarıldığında, adsorpsiyon izotermi elde edilir [20]. Bu çalışmada adsorpsiyon verilerin izoterm analizleri için en yaygın olarak kullanılan Langmuir, Freundlich ve DubininRadushkevich (D-R) izoterm modelleri uygulanmıştır.

Langmuir izoterm modeli, adsorbent yüzeyinde bulunan belli sayıdaki bölgelerin adsorpsiyon sonucunda tek tabaka halinde kaplandığını ve belirli bir madde konsantrasyonunda yüzeyin doygunluğa eriştiğini kabul etmektedir. Langmuir izoterm modeline ait eşitliğin lineer hali Eşitlik 2'de verilmiştir [21].

$\frac{\mathrm{C}_{\mathrm{e}}}{\mathrm{Q}_{\mathrm{e}}}=\frac{1}{\mathrm{Q}_{\mathrm{o}} \cdot \mathrm{b}}+\frac{\mathrm{C}_{\mathrm{e}}}{\mathrm{Q}_{\mathrm{o}}}$

Bu denklemde:

$\mathrm{C}_{\mathrm{e}}$ : Denge anında çözeltide kalan madde konsantrasyonu (mg/L),

$\mathrm{q}_{\mathrm{e}}$ : Denge anında adsorbentin birim kütlesi başına adsorplanan madde miktarı $(\mathrm{mg} / \mathrm{g})$,

$\mathrm{Q}_{\mathrm{o}}$ : Langmuir adsorpsiyon kapasitesi (mg/g),

b: Langmuir adsorpsiyon sabiti (L/mg)'dir.

$\mathrm{C}_{\mathrm{e}}$ 'ye karşı $\mathrm{C}_{\mathrm{e}} / \mathrm{q}_{\mathrm{e}}$ 'nin grafiğe aktarılması sonucunda elde edilen doğrunun y eksenini kestiği nokta $1 /\left(Q_{0} . b\right)$ 'yi, doğrunun eğimi ise $1 / Q_{0}$ 'yi verir.

Adsorbent yüzeyinin homojen olmamas1 durumunda ve adsorplanan maddenin tanecikleri arasında etkileşim olması halinde, adsorpsiyon sistemi Langmuir izoterm modelinden sapmalar göstermektedir. Böyle durumlarda, bazı ampirik izoterm modelleri kullanılmaktadır. Bunlardan en yaygın kullanılanı ise Freundlich izoterm modelidir. $\mathrm{Bu}$ modele ait eşitliğin lineer hali Eşitlik 3'de verilmiştir [22].

$\log \mathrm{q}_{\mathrm{e}}=\log \mathrm{k}+\frac{1}{\mathrm{n}} \log \mathrm{C}_{\mathrm{e}}$ 
Bu denklemde:

$\mathrm{C}_{\mathrm{e}}$ : Denge anında adsorplanmadan çözeltide kalan madde konsantrasyonu ( $\mathrm{mg} / \mathrm{L})$,

$\mathrm{q}_{\mathrm{e}}$ : Denge anında birim adsorbent kütlesi başına adsorplanan madde miktarı $(\mathrm{mg} / \mathrm{g})$,

$\mathrm{k}$ : Freundlich $\left[(\mathrm{mg} / \mathrm{g}) \cdot(\mathrm{mg} / \mathrm{L})^{-1 / \mathrm{n}}\right]$ adsorpsiyon

kapasitesi

n: Freundlich adsorpsiyon sabiti (L/mg)'dir.

Freundlich izoterm modeline ait $\mathrm{k}$ ve $\mathrm{n}$ değerleri, $\log \mathrm{C}_{\mathrm{e}}$ 'ye karşı $\log \mathrm{q}_{\mathrm{e}}$ 'nin grafiğe aktarılması sonucu elde edilen doğrunun sirasiyla y eksenini kestiği noktadan ve eğiminden hesaplanmaktadır.

Dubinin-Radushkevich (D-R) izotermi, Polanyi adsorpsiyon potansiyeline dayanan bir modeldir. Eşitlik 4'te gösterilen bu izoterm adsorpsiyon prosesinin fiziksel veya kimyasal olup olmadığ 1 hakkında bilgi vermektedir [23].

$\ln q_{e}=\ln X_{m}^{\prime}-K^{\prime} \varepsilon^{2}$

Bu denklemde:

$\varepsilon \quad$ : Polanyi potansiyelini [RT $\ln \left(1+1 / \mathrm{C}_{\mathrm{e}}\right)$ ],

$\mathrm{X}_{\mathrm{m}}$ : Adsorpsiyon kapasitesini (mg/g),

$\mathrm{K}^{\prime}$ : Adsorpsiyon enerjisi ile ilgili sabiti $\left(\mathrm{mol}^{2} / \mathrm{J}^{2}\right)$,

$\mathrm{R}$ : İdeal gaz sabitini [8.314 J/(mol.K)],

$\mathrm{T} \quad$ : Sicaklığı (K)'dir.

Adsorpsiyonun ortalama enerji değeri (E), Eşitlik 4'en elde edilen $\mathrm{K}$ ' değeri kullanılarak $\left[E=\left(-2 K^{\prime}\right)^{-0,5}\right]$ eşitliğine göre hesaplanmaktadır. Hesaplanan $\mathrm{E}$ değerine göre adsorpsiyonun türü hakkında bilgi edinilebilmektedir. E değeri 8-16 $\mathrm{kJ} / \mathrm{mol}$ değerleri arasında yer alırsa adsorpsiyonun iyon değişimine dayandığı ifade edilmektedir. $\mathrm{E}$ değerinin $<8 \quad \mathrm{~kJ} / \mathrm{mol}$ olması durumunda ise van der Waals kuvvetleri ile gerçekleşen fiziksel adsorpsiyondan bahsedilebilir. $16 \mathrm{~kJ} / \mathrm{mol}$ değerinden büyük $\mathrm{E}$ değeri için ise kimyasal adsorpsiyondan söz etmek mümkündür [24].

Aktif karbon ile kongo kırmızısı adsorpsiyonu için Langmuir adsorpsiyon kapasitesi ( $\left.\mathrm{Q}_{\mathrm{o}}\right)$ $117,658 \mathrm{mg} / \mathrm{g}$ ve (b) adsorpsiyon sabiti $0,026 \mathrm{~L} / \mathrm{mg}$ 'dır. Freundlich izoterm modeli için ürünün adsorpsiyon kapasitesi (k) 6,729 (mg/g).(mg/L) $)^{-1 / \mathrm{n}}$, (n) adsorpsiyon sabiti 1,208 olarak hesaplanmıştır. D-R izoterm modelinden hesaplanan adsorpsiyon enerjisi (E) $5,735 \mathrm{~kJ} / \mathrm{mol}$ 'dür. Adsorpsiyon prosesinde, E değerinin $8 \mathrm{~kJ} / \mathrm{mol}$ değerinden daha küçük olduğu için fiziksel adsorpsiyonun etkin olduğunu ifade etmek mümkündür.

Çizelge 2 incelendiğinde ilgili izoterm modellerine ait $\mathrm{R}^{2}$ değerleri, adsorpsiyon verilerinin Langmuir izoterm modeline daha çok uyduğunu göstermektedir. $\mathrm{Bu}$ sonuca göre, elde edilen adsorbentin yüzeyinin homojen özellikte olduğunu ve kongo kırmızısı moleküllerinin adsorbentin yüzeyinde tek tabaka halinde adsorplandığı görülmektedir.

Çizelge 2. Aktif karbon ile kongo kırmızısı adsorpsiyonu için langmuir, freundlich, D-R izoterm modellerine ait sabitler

\begin{tabular}{|c|c|c|c|}
\hline \multicolumn{4}{|c|}{ Langmuir izoterm modeli } \\
\hline $\mathrm{Q}_{\mathrm{o}},(\mathrm{n}$ & & $\mathrm{b},(\mathrm{L} / \mathrm{mg})$ & $\mathrm{R}^{2}$ \\
\hline 117 & & 0,026 & 0,997 \\
\hline \multicolumn{4}{|c|}{ Freundlich izoterm modeli } \\
\hline $\mathrm{k},(\mathrm{mg} / \mathrm{g})$. & $g / L)^{-1 / n}$ & $\mathrm{n}$ & $\mathrm{R}^{2}$ \\
\hline 6,7 & & 1,208 & 0,928 \\
\hline \multicolumn{4}{|c|}{ D-R izoterm modeli } \\
\hline $\mathrm{Xm}, \mathrm{mol} / \mathrm{g}$ & $\mathrm{K}^{\prime}$ & $\mathrm{E}, \mathrm{kj} / \mathrm{mol}$ & $\mathrm{R}^{2}$ \\
\hline 5,446 & 0,0152 & 5,735 & 0,990 \\
\hline
\end{tabular}

Çizelge 3. Literatürde farklı başlangıç maddelerinden elde edilen aktif karbonların yüzey alanları ve kongo kırmızı için langmuir adsorpsiyon kapasiteleri

\begin{tabular}{|l|c|c|}
\hline \multicolumn{1}{|c|}{ Adsorbent } & $\begin{array}{c}\mathbf{Q}_{\mathbf{o}}, \\
(\mathbf{m g} / \mathbf{g})\end{array}$ & Kaynak \\
\hline $\begin{array}{l}\text { Eupatorium adenophorum } \\
\text { (Kimyasal metot, } \mathrm{H}_{3} \mathrm{PO}_{4} \text { ) }\end{array}$ & 351 & {$[25]$} \\
\hline $\begin{array}{l}\text { Domates bitkisi sap1 } \\
\text { (Kimyasal metot, } \mathrm{FeCI}_{2} \text { ) }\end{array}$ & 158,73 & {$[26]$} \\
\hline Aktif karbon & $\mathbf{1 1 7 , 6 5}$ & $\begin{array}{c}\text { Bu } \\
\text { çalışma }\end{array}$ \\
\hline Hünnap kabuğu & 80,49 & {$[27]$} \\
\hline Neem yaprağ1 tozu & 72,4 & {$[28]$} \\
\hline Buğday sap1 & 73,4 & {$[29]$} \\
\hline $\begin{array}{l}\text { Kayısı Çekirdeği } \mathrm{Kabuğu}_{\text {(Kimyasal metot, } \mathrm{H}_{3} \mathrm{PO}_{4} \text { ) }} \\
\text { (Kimyal }\end{array}$ & 32,85 & {$[30]$} \\
\hline
\end{tabular}



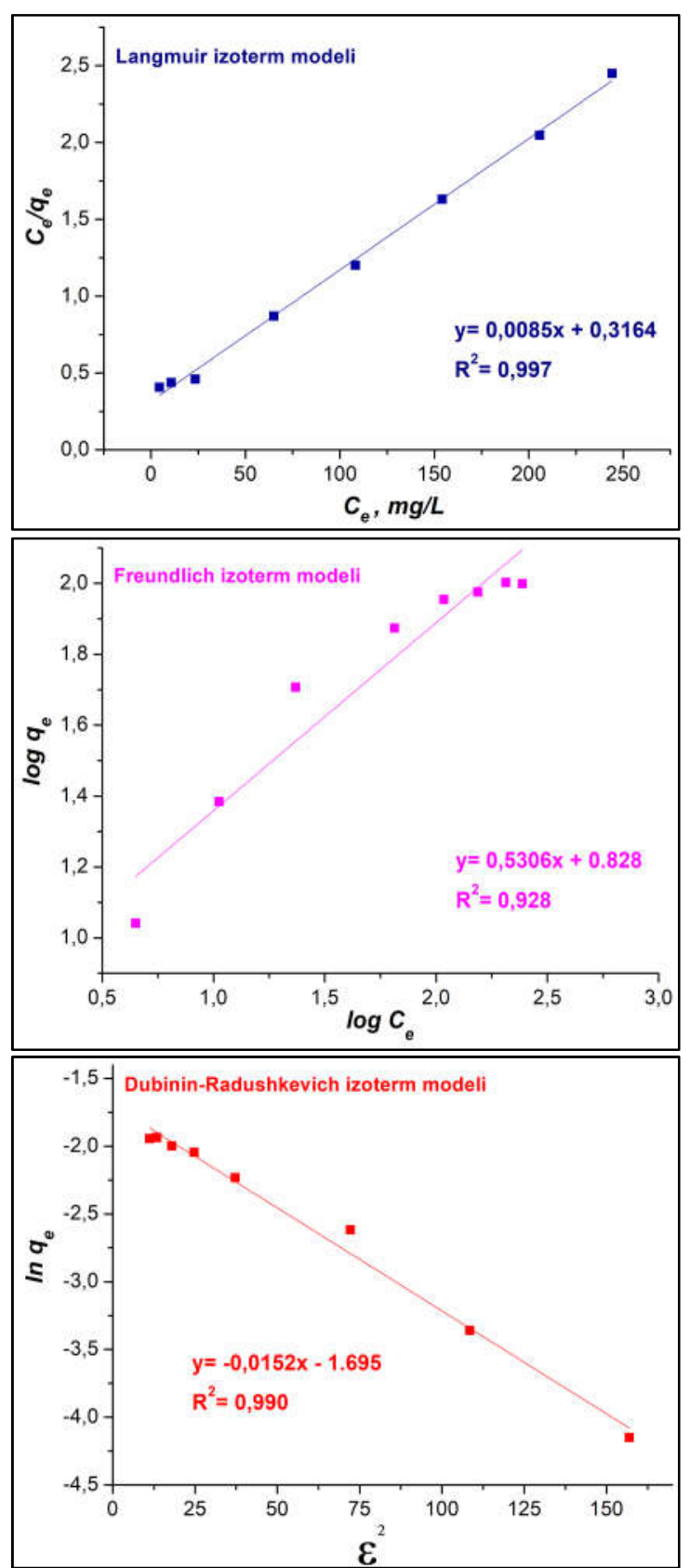

Şekil 8. Aktif karbon ile kongo kırmızısı adsorpsiyonu için Langmuir, Freundlich, D-R izoterm modelleri (Co: $10-300 \mathrm{mg} / \mathrm{L}$, pH: 7,02-7,10, temas süresi: 60 dakika, adsorbent miktarı: $0,5 \mathrm{~g} / \mathrm{L}$, sicaklık: $25{ }^{\circ} \mathrm{C}$, iyonik şiddet: $0,01 \mathrm{M}$, karıştırma h1z1: $220 \mathrm{rpm}$ )
Kongo kırmızısı için aktif karbon ürününün Langmuir adsorpsiyon kapasitesi $(117,658 \mathrm{mg} / \mathrm{g}$ ) ile literatürdeki aktif karbonların kapasiteleri Çizelge 3'de karşılaştırılmıştır. Elde edilen aktif karbonun pek çok adsorbentten daha yüksek adsorpsiyon kapasitesine sahip olduğu belirtilmiştir.

\subsubsection{Yeniden Kullanılabilirlik}

Aktif karbonun yeniden kullanılabilme özelliği belirlenebilmesi için desorpsiyon işlemi gerçekleştirilmiştir. Desorpsiyon işlemi, uygun çözücülerin kullanımı ile katı-sıvı ekstraksiyon yöntemleri ve $\mathrm{pH}$ değişimi ile yapılmaktadır [31].

Başlık 3.3.1'de adsorbentin kongo kırmızısı gideriminde çözeltinin $\mathrm{pH}$ değerinden etkilenmediği belirtilmiştir. $\mathrm{Bu}$ sebepten, desorpsiyon işleminde katı-sıvı ekstraksiyon yöntemi tercih edilmiştir. Katı-sıvı ekstraksiyon yönteminde desorpsiyon işlemi için çözücü olarak etanolün kullanılabileceği (Chern ve $\mathrm{Wu}, 2001)$ ve (Alatalo ve ark., 2016) tarafından gösterilmiştir [31,32]. Etanolün kullanım avantaj1, oda sıcaklığında buharlaştırılması ve desorbe edilen boyar maddelerin yeniden kullanılabilmesidir.

$\mathrm{Bu}$ bilgilere göre, $25 \mathrm{mg} / \mathrm{L}$ kongo kırmızıs1 adsorpsiyonun da kullanılan $0,5 \mathrm{~g} / \mathrm{L}$ miktarındaki Aktif karbonun desorpsiyonu 15 dakika süresince $10 \mathrm{~mL}$ etanol ile yıkanarak gerçekleştirilmiştir. Desorpsiyon çözeltisinden uzaklaştırılan ve oda sicaklığında kurutulan Aktif karbon adsorpsiyondesorpsiyon döngülerinde kullanılmıştır. Elde edilen sonuçlar Şekil 9'da gösterilmiştir.

Aktif karbonun giderim veriminde bir değişim olmadan en az $6 \mathrm{kez}$ adsorpsiyon-desorpsiyon döngüsünde kullanılabileceği belirlenmiştir. $\mathrm{Bu}$ sonuca göre, desorbe edilen adsorbentin kongo kırmızısı giderimin de yeniden kullanılabilir olduğu ifade edilebilir. 


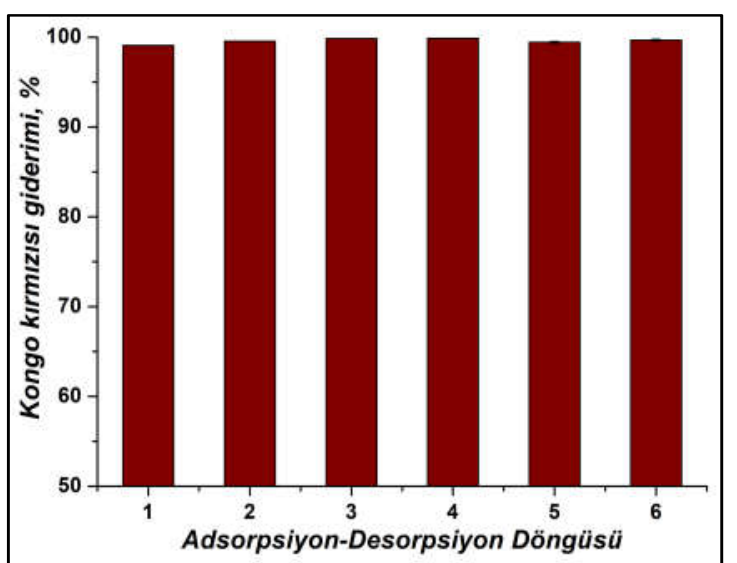

Şekil 9. Aktif karbon'un kongo kırmızısı gideriminde yeniden kullanılabilme potansiyeli (Desorpsiyonda kullanılan çözücü: etanol, adsorpsiyon prosesi için $\mathrm{C}_{\mathrm{o}}: 25 \mathrm{mg} / \mathrm{L}$, temas süresi: 1 saat, pH: 7,00-7,10, adsorbent miktarı: $0,5 \mathrm{~g} / \mathrm{L}$, iyonik şiddet: $0,01 \mathrm{M}$, sicaklık: $25{ }^{\circ} \mathrm{C}$, karıştırma hızı: $220 \mathrm{rpm}$ )

\section{SONUÇLAR VE ÖNERİLER}

Yapılan bu çalışmada doğal bir madde olan nişasta hidrotermal karbonizasyon (HTC) tekniği ile karbonca zengin bir ürüne dönüştürülmüştür. Ardından $\mathrm{NaOH}$ ile kimyasal aktivasyon işlemi ile yüksek yüzey alanına sahip aktif karbon elde edilmiştir. Nişastanın hidrotermal karbonizasyonu sonucu elde edilen karbon küreciğin yüzey alanı $\left(4 \mathrm{~m}^{2} / \mathrm{g}\right)$ ve toplam gözenek hacmine $\left(0,001 \mathrm{~cm}^{3} / \mathrm{g}\right)$ sahiptir. $\mathrm{NaOH}$ ile kimyasal aktivasyonu sonucu elde edilen aktif karbonun ise oldukça yüksek yüzey alanına $\left(968 \mathrm{~m}^{2} / \mathrm{g}\right)$ ve toplam gözenek hacmine $\left(0,684 \mathrm{~cm}^{3} / \mathrm{g}\right)$ sahip adsorbent elde edilmiştir. Ürünlerin yapısal ve morfolojik değişimleri FT-IR, SEM ve BET yüzey alanı ve gözenek boyut dağılımı teknikleri ile incelenmiştir. Kongo kırmızısı ile gerçekleştirilen denemeler sonucunda, adsorbent olarak etkili bir şekilde kullanılabileceği sonucuna ulaşılmıştır. Adsorbentin kongo kırmızısı için Langmuir adsorpsiyon kapasitesinin (117,65 $\mathrm{mg} / \mathrm{g})$ literatürdeki birçok karbon esaslı adsorbentten daha yüksek olduğu tespit edilmiştir. Adsorbentin çözelti pH'ından bağımsız bir şekilde kongo kırmızısı adsorpsiyonunda kullanılabilmesi, pratik uygulamalar için önemli bir avantaj olarak değerlendirilmiştir. Ayrıca adsorbentin giderim kapasitesinde bir azalma olmadan en az $6 \mathrm{kez}$ adsorpsiyon desopsiyon döngüsünde kullanılabilir özellikte olduğu görülmüştür.

\section{KAYNAKLAR}

1. Abbasa, M., Trari, M., 2015. Kinetic, Equilibrium and Thermodynamic Study on the Removal of Congo Red from Aqueous Solutions By Adsorption onto Apricot Stone, Process Saf. Environ. Prot., 98, 424-436.

2. Duman, O., Tunç, S., Polat, T.G., Bozoglan, B.K., 2016. Synthesis of Magnetic Oxidized Multiwalled Carbon Nanotube-K-carrageenan$\mathrm{Fe}_{3} \mathrm{O}_{4}$ Nanocomposite Adsorbent and its Application in Cationic Methylene Blue Dye Adsorption, Carbohydr. Polym., 147, 79-88.

3. Kobya, M., Bayamoglu, M., Eyvaz, M., 2007. Techno-economical Evaluation of Electrocoagulation for the Textile Wastewater Using Different Electrode Connections, J. Hazard. Mater., 148, 311-318.

4. Liu, M., Chen, Q., Lu, K., Huang, W., Lü, Z., Zhou, C., Yu, S., Gao C., 2017. High Efficient Removal of Dyes from Aqueous Solution Through Nanofiltration Using DiethanolamineModified Polyamide Thin-film Composite Membrane, Sep. Purif. Technol., 173, 135-143.

5. Bedin, K.C., Martins, A.C., Cazetta, A.L., Pezoti, O., Almeida V.C., 2016. KOHactivated Carbon Prepared from Sucrose Spherical Carbon: Adsorption Equilibrium, Kinetic and Thermodynamic Studies for Methylene Blue Removal, Chem. Eng. J., 286, 476-484.

6. Yin, J., Pei, M., He, Y., Du, Y., Guo, W., Wang, L., 2015. Hydrothermal and Activated Synthesis of Adsorbent Montmorillonite Supported Porous Carbon Nanospheres for Removal of Methylene Blue from Waste Water, RSC Adv., 5, 89839-89847.

7. Tongur, S., Aydin M.E., 2013. Adsorption Kinetics of Chloroform Aqueous Solutioins onto Activated Lignite. Clean-Soil, Air, Water, 41,1-5. 
8. Li, M., Wang, S., Luo, W., Xia, H., Gao, Q., Zhou, C., 2015. Facile Synthesis and in Situ Magnetization of Carbon-decorated Lignocellulose Fiber for Highly Efficient Removal of Methylene Blue, J. Chem. Technol. Biotechnol., 90,1124-1134.

9. Xiao, H., Guo, Y., Liang, X., Qi, C., 2010. One-step Synthesis of Novel Biacidic Carbon Via Hydrothermal Carbonization, J. Solid State Chem., 183, 1721-1725.

10. Kazak, O., Eker, Y.R., Bingol, H., Tor, A., 2018. Preparation of Chemically-activated High Surface area Carbon from Waste Vinasse and its Efficiency as Adsorbent Material, J. Mol. Liq., 272, 189-197.

11. Kazak, O., Eker, Y.R., Akın, I., Bingol, H., Tor, A., 2017. Green Preparation of a Novel Red Mud@carbon Composite and its Application for Adsorption of 2,4dichlorophenoxyacetic Acid from Aqueous Solution, Environ. Sci. Pollut. Res., 24, 23057-23068.

12. Szymański, S., Karpinski, Z., Biniak, S., Swiatkowski, A., 2002. The Effect of the Gradual Thermal Decomposition of Surface Oxygen Species on the Chemical and Catalytic Properties of Oxidized Activated Carbon, Carbon, 40, 2627-2639.

13. Cheng, F., Luo, H., Hu, L., Yu, B., Luo, Z., Fidalgo de Cortalezzi, M., 2016, Sludge Carbonization and Activation: From Hazardous Waste to Functional Materials Forwater Treatment. J. Environ. Chem. Eng., 4, 4574-4586.

14. Lin, Y., Liao, Y., Yu, Z., Fang, S., Lin, Y., Fan, Y., Peng, X., Ma, X., 2016. Co-pyrolysis Kinetics of Sewage Sludge and Oil Shale Thermal Decomposition Using TGA-FTIR analysis, Energy. Conversion. Manage. 118, 345-352.

15. Unur, E., 2013. Functional Nanoporous Carbons from Hydrothermally Treated Biomass for Environmental Purification, Microporous Mesoporous Mater., 168, 92-101.

16. Yan, Q., Street, J., Yu, F. 2015. Synthesis of Carbon-encapsulated Iron Nanoparticles from Wood Derived Sugars by Hydrothermal Carbonization (HTC) and Their Application to
Convert Bio-syngas into Liquid Hydrocarbons, Biomass and Bioenergy 83, 85-95.

17. Li, J., Dickon, H.L. Ng, D.H.L, Song, P., Kong, C., Song, Y., Yang, P., 2015. Preparation and Characterization of Highsurface-area Activated Carbon Fibers from Silkworm Cocoon Waste for Congo Red Adsorption, Biomass and Bioenergy 75, 189-200.

18. Dong, W., Lu, Y., Wang, W., Zong, L., Zhu, Y., Kang, Y., Wang, A., 2019. A New Route to Fabricate High-efficient Porous Silicate Adsorbents by Simultaneous Inorganic-organic Functionalization of Low-grade Palygorskite Clay for Removal of Congo Red, Microporous Mesoporous Mater., 277, 267-276.

19. Cheng, F., Luo, H., Hu, L., Yu, B., Luo, Z., Fidalgo de Cortalezzi, M., 2016. Sludge Carbonization and Activation: From Hazardous Waste to Functional Materials Forwater Treatment, J. Environ. Chem. Eng., 4, 4574-4586.

20. Chiou, C.T., 2002. Fundamentals of the Adsorption Theory: in Partition and Adsorption of Organic Contaminants in Environmental Systems, John Wiley \& Sons, Inc., 39-52.

21. Langmuir, I., 1916. The Constitution and Fundamental Properties of Solids Andliquids, Part I. Solids, J. Am. Chem. Soc., 38, 2221-2295.

22. Freundlich, H.M.F., 1906. Über die Adsorption in Lösungen, Z., Phys. Chem., 385-470.

23. Dubinin, M.M., 1966. Chemistry and Physics of Carbon, 2, 51, Dekker, New York.

24. Dubinin, M.M., Radushkevich, L.V., 1947. The Equation of the Characteristic Curve of Activated Charcoal. Proceedings of the Academy of Sciences, Physical Chemistry Section, 55, 331.

25. Li, C., Zhang, L., Xia, H., Peng, J., Zhang, S, Cheng, S., Shu J., 2016. Kinetics and Isotherms Studies for Congo Red Adsorption on Mesoporous Eupatorium Adenophorum-based Activated Carbon Via Microwave-induced $\mathrm{H}_{3} \mathrm{PO}_{4}$ Activation, J. Mol. Liq., 224, 737-744.

26. Fu, K.F., Yue, Q.Y., Gao, B.Y., Wang, Y., Li, Q., 2017. Activated Carbon from Tomato Stem By Chemical Activation with $\mathrm{FeCl}_{2}$, Colloids Surf. A Physicochem. Eng. Asp., 529, 842-849. 
27. El Messaoudi, N., El Khomri, M., Dbik, A., Bentahar, S., Lacherai, A., Bakiz, B., 2016. Biosorption of Congo Red in a Fixed-bed Column from Aqueous Solution Using Jujube Shell: Experimental and Mathematical Modeling, J. Environ. Chem. Eng., 4(4), 3848-3855.

28. Panda, G.C., Das, S.K., Guha, A.K., 2009. Jute Stick Powder as a Potential Biomass for the Removal of Congo Red and Rhodamine $\mathrm{B}$ from their Aqueous Solution, J. Hazard. Mater., 164, 374-379.

29. Wang, Z.W., Han, P., Jiao, Y.B., He, X.T., Dou, C.C., Han, R.P., 2011. Adsorption of Congo Red Using Ethylenediamine Modified Wheat Straw, Desalination Water Treatment, 30, 195-206.

30. Abbas, M., Trari, M., 2015. Kinetic, Equilibrium and Thermodynamic Study on the Removal of Congo Red from Aqueous Solutions By Adsorption onto Apricot Stone, Process Saf. Environ. Prot., 98, 424-436.

31. Alatalo, S.M., Mäkilä, E., Repo, E., Heinonen, M., Salonen, J., Kukk E., 2016. Mesoand Microporous Soft Templated Hydrothermal Carbons for Dye Removal from Water, Green Chem., 18, 1137-1146.

32. Chern, J.M., Wu, C.Y., 2001. Desorption of Dye from Activated Carbon Beds: Effects of Temperature, $\mathrm{pH}$ and Alcohol, Water Res., 35, 4159-4165. 
